\title{
Resolving Disconnected Patient Records to Support Patient Care and Population Health
}

\author{
Jacob Krive ${ }^{2,3,4}$, Annamarie Hendrickx ${ }^{* 1}$ and Terri Godar ${ }^{1}$ \\ ${ }^{1}$ Advocate Health Care, Rolling Meadows, IL, USA; ${ }^{2}$ Valence Health, Chicago, IL, USA; ${ }^{3}$ University of Illinois at Chicago, Chicago, IL, \\ USA; ${ }^{4}$ Nova Southeastern University, Fort Lauderdale, FL, USA
}

\section{Introduction}

Population health relies on tracking patients through a continuum of care with data from disparate sources. An assumption is made that all records of a patient from all the sources are connected ${ }^{1}$. As was realized during the process of operationalizing algorithms for population health, not all patient records are connected ${ }^{2}$. Disconnected records negatively impact results: from individual patient care management through population health's predictive analytics ${ }^{3,4}$. An enterprise master patient index (EMPI) system can be employed to connect a patient's records across disparate systems ${ }^{5}$, but it requires comprehensive tuning to maximize the number of connected records. This presentation describes how one large healthcare integrated delivery network tuned their EMPI system to maximize the number of connected patient records across all sources.

\section{Methods}

Several methods were employed to reduce the number of disconnected records. The 5 sources containing the most disconnected records were chosen from the 32 sources of data in the system that represented 10.5 million records. Retention rules were developed for removing records from the EMPI database that did not meet the criteria for retention and those records were removed. Using sampled data, the weighting factors applied to the data elements used to determine a score to allow the EMPI system to link records together (autolink), and the score at which an autolink occurs were reconfigured to allow the EMPI system to link more records. The matching algorithm was enhanced for combining the patient records into a single entity for sources that were sending a high rate of duplicate patient records with differing patient IDs and identical demographics. A crossmatching function was executed to force the re-evaluation of all the linkages between all the records within the EMPI database. The Data Stewardship Team used the Delphi method to determine false positive and false negative rates.

\section{Results}

The number of disconnected records was reduced by $99.8 \%$ (Tables 1, 2, 3)

\section{Conclusions}

An IDN can employ several tactics to address unmatched patient records across multiple sources without manually reviewing all patient records for possible matches. This project represented the first pass of data standardization and reconciliation. During project execution, additional data quality issues were discovered. This led to a number of follow-on interventions, such as the development of a new source onboarding policy, development of a go-live data validation checklist, inclusion of third party software to validate addresses, and developing guidelines for reducing data errors and the number of duplicate patient records sent to the EMPI system at patient intake.
Table 1. EMPI Drop Records Statistics

\begin{tabular}{|c|c|c|c|c|c|c|}
\hline $\begin{array}{c}\text { Advocate } \\
\text { Source of } \\
\text { Information }\end{array}$ & $\begin{array}{c}\text { Records } \\
\text { Original }\end{array}$ & $\begin{array}{c}\text { Records } \\
\text { Dropped }\end{array}$ & $\begin{array}{c}\text { Records } \\
\text { Reloaded } \\
\text { Back Into } \\
\text { EMPI } \\
\text { System }\end{array}$ & $\begin{array}{c}\text { Records } \\
\text { Remaining } \\
\text { Per Source }\end{array}$ & $\begin{array}{c}\text { Number of } \\
\text { Disconnected } \\
\text { Records } \\
\text { Before Drop }\end{array}$ & $\begin{array}{c}\text { Number of } \\
\text { Disconnected } \\
\text { Records } \\
\text { After Drop }\end{array}$ \\
\hline Source 1 & $1,899,469$ & $\mathbf{1 , 8 9 9 , 4 6 9}$ & 267,645 & 267,645 & $3,277,289$ & $2,048,322$ \\
\hline Source 2 & 122,519 & 122,519 & - & 0 & $2,048,322$ & $2,035,808$ \\
\hline Source 3 & 283,259 & 22,678 & - & 260,581 & $\mathbf{1 , 9 8 2 , 8 1 9}$ & $1,979,287$ \\
\hline Source 4 & 233,058 & 94,444 & - & 138,614 & $\mathbf{1 , 9 7 9 , 2 8 7}$ & $1,973,809$ \\
\hline Source 5 & $2,045,208$ & 662,731 & - & $1,382,477$ & $\mathbf{1 , 9}, 920,652$ & $1,859,692$ \\
\hline Total & $4,583,513$ & $2,801,841$ & 267,645 & $2,049,317$ & & \\
\hline
\end{tabular}

Table 2. EMPI Cross-Match Statistics|

\begin{tabular}{|c|c|c|}
\hline Source & $\begin{array}{c}\text { Number of Disconnected Records } \\
\text { Before Cross-Match }\end{array}$ & $\begin{array}{c}\text { Number of Disconnected Records } \\
\text { After Cross-Match }\end{array}$ \\
\hline All Sources & $1,859,692$ & 396,569 \\
\hline
\end{tabular}

Table 3. EMPI Final Statistics

\begin{tabular}{|c|c|c|c|}
\hline Source & $\begin{array}{c}\text { Starting Number of } \\
\text { Disconnected Records }\end{array}$ & $\begin{array}{c}\text { Ending Number of } \\
\text { Disconnected Records }\end{array}$ & $\begin{array}{c}\text { Percent } \\
\text { Reduction }\end{array}$ \\
\hline All Sources & $3,277,289$ & 396,569 & $99.8 \%$ \\
\hline
\end{tabular}

Keywords

Enterprise Master Patient Index; Patient Data Linkage; Data Governance

\section{References}

[1] Goth G. Running on EMPI. Health information exchanges and the ONC keep trying to find the secret sauce of patient matching. Health Data Manag 2014 Feb;22(2):52, 54, 56 passim.

[2] Anderson HJ. Curing an integration headache. Health Data Manag $2009 \mathrm{Jul} ; 17(7): 38$.

[3] Albright B. The power of EMPI. Health systems are tapping the value of EMPIs to eliminate duplicate patient records. Healthc Inform 2008 Apr;25(4):28-30.

[4] Harron K, Wade A, Gilbert R, Mueller-Peabody B, Goldstein H, Evaluating bias due to data linkage error in electronic health records. BMC Med Res Methodol 2014;14:36

[5] Martin Z. A new application for biometrics. Health Data Manag 2007; 15:46-48.

*Annamarie Hendrickx

E-mail: annamarie.hendrickx@advocatehealth.com 